EVIDENCE BASED PUBLIC HEALTH POLICY AND PRACTICE

\title{
Disease profile of children in Kabul: the unmet need for health care
}

\section{Amarendra Narayan Prasad}

J Epidemiol Community Health 2006;60:20-23. doi: 10.1136/jech.2005.040147

This study was conducted at the paediatric emergency department of a tertiary care teaching and referral hospital in Kabul, Afghanistan to assess the morbidity and mortality pattern of illness in paediatric population. Afghanistan has one of the highest infant mortality rates in the world, and there is complete breakdown of the health care system in the country because of the continued war. A total of 17850 children and neonates were seen at the paediatric emergency centre at IGICH, Kabul in one year period from 18 September 2002 to 17 September 2003. The most common illnesses were diarrhoea and respiratory infections. Infectious diseases, neonatal illnesses, and cardiac diseases were other important causes of morbidity. Neonatal deaths formed the major proportion of all deaths. Morbidity and mortality attributable to easily preventable/curable diseases was quite high. There is an urgent need to develop an integrated and effective health care system in the country.

$\mathrm{T}$ he health care system for children in Afghanistan is barely functioning. Twenty years of armed conflict have decimated the country. Here, the United Nations Convention on the "Rights of the Child" has no meaning. Maternal and child health care are sparse and mostly in urban areas where they are run by international aid agencies rather than the local government. The appalling statistics on infant, child, and maternal mortality rates speak for themselves, but even these are probably an underestimate of the true figures, as most of the population never receive the attention of a health care worker.

Afghanistan has one of the highest infant mortality rates in the world. With the child population (10 740 000) constituting $42 \%$ of the population, the infant mortality rate is $165 / 1000$ live births and the under 5 mortality rate is 257/ $1000 .^{2}$ Forty one per cent of childhood deaths were attributable to diarrhoeal diseases and acute respiratory infections. ${ }^{3}$ Septicaemia and CNS infections were associated with high mortality, especially among the neonates. Birth asphyxia is largely untreated. Excessive numbers of infants are born with congenital abnormalities, which are probably the result of maternal malnutrition during early fetal development. ${ }^{4}$

Built in 1972, and later supported by the Indian government, Indira Gandhi Institute of Child Health, Kabul is the main childrens hospital in the country. It now has 250-300 beds, and is fully occupied most of the time. Diagnostic capabilities are limited and rarely available, making diagnosis dependent on clinical skills and guesswork. The practice of reasonable standard of paediatric medicine is difficult.

With this background, this study was conducted to evaluate the extent and pattern of disease morbidity and mortality of children in Afghanistan.

\section{METHODS}

A retrospective analysis of records of patients (less than 12 years) attending the paediatric emergency service in Indira Gandhi Institute of Child Health (IGICH), Kabul, Afghanistan over a 12 month period from 18 September 2002 to 17 September 2003 was conducted.

IGICH, Kabul is a tertiary referral centre for patients from all over the country and seriously ill children from Kabul and its suburbs are admitted here. The Indian government donated equipment to the hospital in 1980s and gave it its present name. It had academic links with AIIMS, Delhi. It now has 250-300 beds and consists of paediatric medicine, paediatric surgery, ENT, and neonatal medicine. Apart from minute input from international donors, there is an almost complete absence of medical equipments and supplies. A doctor's salary is 40 dollars per month, and often the government does not have the money to pay even this small amount. Moreover, the doctors are extremely demoralised. Mothers undertake most of the nursing, and sleep on the floor next to each bed. The children stay in their street clothes and during busy times of the year there may be two to three children on each bed (see figs 1 and 2).

Paediatric emergency is staffed around the clock by four trainee residents, one senior resident (trained postgraduate paediatrician) along with nursing staff. Patient diagnosis and clinical data were verified and entered by the medical officer on duty in the emergency. Data were analysed using descriptive statistics-frequency and proportions-and compared by using $\chi^{2}$ test and level of significance was set at 0.05 .

Most patients coming to the paediatric emergency unit are not referred but come directly. The emergency unit operates 24 hours a day, has laboratory support, and radiographic resources. About 1500 patients are seen in the paediatric emergency service every month. Cases of paediatric trauma and other obvious surgical emergencies were sent directly to paediatric surgical emergency and are not considered in this study. High risk neonates are brought or referred here, and no deliveries take place in this hospital (there are separate hospitals for antenatal mother care and deliveries, with only female staff and doctors, because of the sex discrimination existing there).

Diagnosis was based mainly on clinical criteria, for the obvious reasons of feasibility and availability of diagnostic tests. Hence some of the diagnoses should be considered presumptive.

\section{RESULTS}

A total of 17850 children were seen during the 12 month period. Table 1 shows the age and sex distribution of patients. Male to female ratio was 60:40. The most important causes of morbidity in children ( 1 month to 12 years) were acute respiratory infection and diarrhoea, accounting for $36 \%$ of all cases (table 2). Other important causes of morbidity included infectious diseases and cardiac emergencies, together 

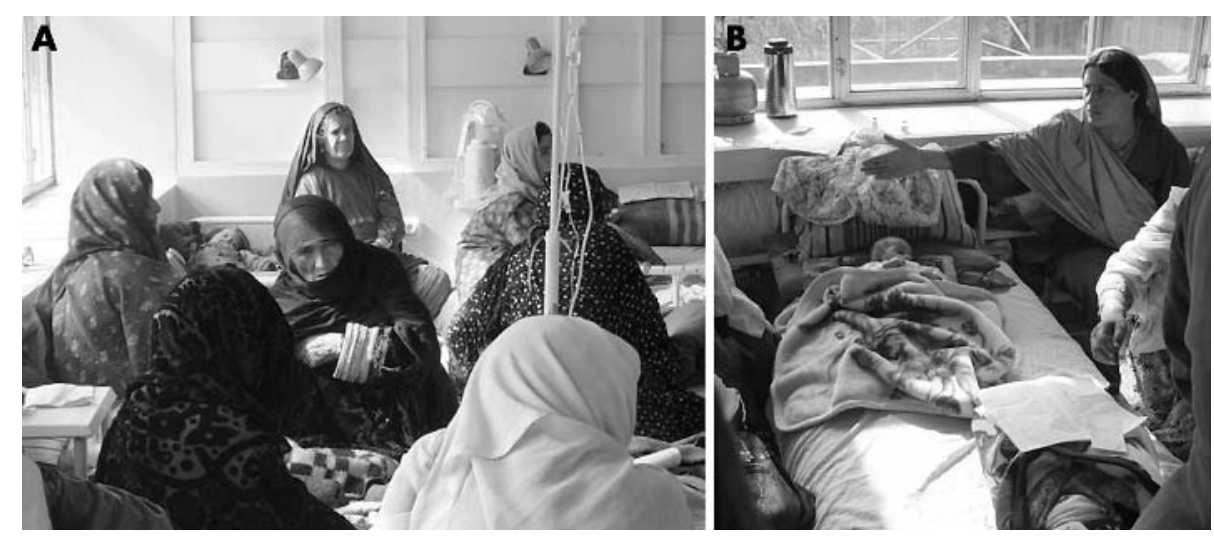

Figure 1 The crowded emergency ward of the hospital showing two children being treated in one bed and the sick attendants and mothers of patients close by, with no separate bed for them.

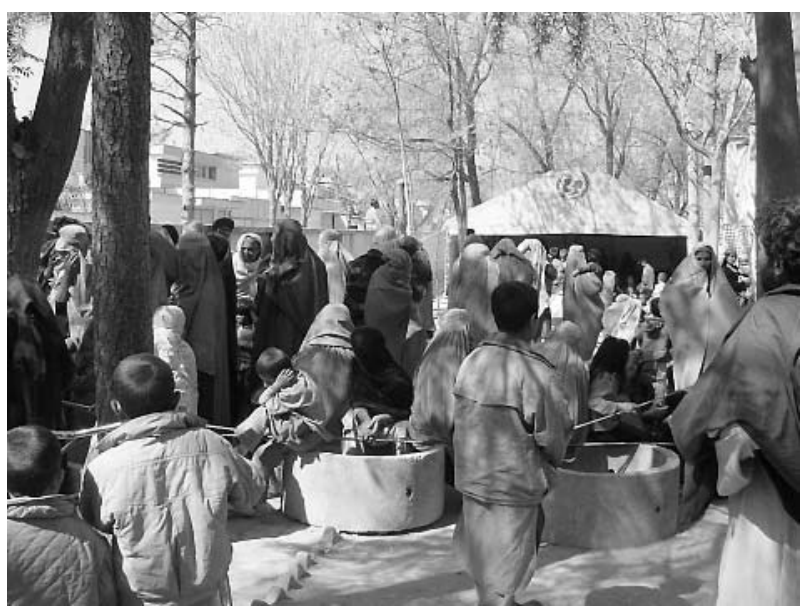

Figure 2 The long patient queve in the registration area of the paediatric outpatient department of the IGICH hospital.

accounting for $26 \%$ cases. There was a high incidence of Down's syndrome, probably because mothers continue to have children until an elderly age. Metabolic and other genetic disorders were also common (consanguineous marriage was quite common in society). Table 3 gives the distribution of various high risk health problems in neonates. Nearly $21 \%$ neonates were before term, weighing less than 2500 g. Many neonates and children had more than one illness, and hence they have appeared more than once under different causes of morbidity in the table.

The overall mortality was $14.8 \%$. Maximal mortality rate was in the neonatal period. Major cause of neonatal mortality was birth asphyxia, sepsis, respiratory distress, and prematurity. Mortality in older children was primarily contributed by pneumonia, bronchiolitis, diarrhoea, sepsis, cardiovascular illnesses like congestive cardiac failure and CHD, shock, and CNS diseases like pyogenic meningitis and encephalitis (see tables 4 and 5).

\section{DISCUSSION}

This study was done to generate data that can help in understanding the health care needs in Afghanistan and help the health managers to plan rational distribution of resources. The lasting impact of war on the health status of children can well be seen here. The lack of basic needs such as food, shelter, clean water, health care access, education, and work opportunities is the biggest health challenge. ${ }^{5}$ Another notable constraint is lack of human resources. The lack of trained health professionals is arguably the single greatest problem. ${ }^{6}$ Despite intense recruiting efforts it has been extremely difficult to find physicians to work in rural areas. In the face of still developing case definitions and extremely limited laboratory support, diagnoses are usually made on the basis of patients self reported symptoms (although some of the patients made use of the diagnostic facilities across the border in Pakistan, of which Peshawar was closest). Sex status seems to affect even paediatric access to health care; shown by the fact that most $(59.9 \%)$ paediatric consultations involved boys. Medical education has been halted with few publications or books later than 1986 available. Although relative peace has returned to some areas of the country, the economy is so weak that little can be done by the ruling authorities to improve the situation. ${ }^{7}$

IGICH is the main childrens hospital in Afghanistan and seriously ill children were admitted here from Kabul and its suburbs, and the hospital served as a tertiary referral centre for patients from all over the country. On average, four children die each day in IGICH, Kabul of preventable/easily treatable illnesses. Among the infectious diseases gastroenteritis accounted for nearly $20 \%$ of the admissions. Septicaemia, meningitis, pneumonia, tuberculosis, measles, and typhoid fever were other common infectious diseases. Malnutrition of varying degree was the core problem, and was seen in nearly one quarter of admissions. Twenty per cent of them had severe PEM, which contributed for higher mortality. Septicaemia and CNS infections were associated with high mortality especially among neonates.

The lasting impact of war on the psychological state of children is well described. Many children have post-traumatic

Table 1 Age and sex distribution of children seen at emergency of IGICH, Kabul (total number $=17850$ )

\begin{tabular}{llll}
\hline Age group & Male & Female & Total \\
\hline $0-30$ days & 3200 & 2650 & 5850 \\
$1-12$ months & 2480 & 1396 & 3876 \\
$12-60$ months & 3840 & 2625 & 6465 \\
$5-12$ years & 1180 & 479 & 1659 \\
\hline
\end{tabular}


Table 2 Causes of morbidity in children ( 1 month-12 years) (total number $=12000$ )

\begin{tabular}{|c|c|c|c|}
\hline Disease system & Disease condition* & $\begin{array}{l}\text { Number } \\
\text { of cases }\end{array}$ & $\%$ \\
\hline CNS & $\begin{array}{l}\text { †-cerebral palsy, seizures, stroke, hydrocephalus, neural tube defect, Sydenham's chorea } \\
\ddagger \text { - migraine, neurodegenerative disorders, neurocutaneous syndromes, muscular dystrophy, } \\
\text { myasthenia gravis, Guillane Barre syndrome }\end{array}$ & $\begin{array}{l}848 \\
106\end{array}$ & 8 \\
\hline Urinary system & $\begin{array}{l}\text { C-nephrotic syndrome, glomerulonephritis, urinary tract infection, urolithiasis } \\
\text { O-renal failure, obstructive uropathy, renal tubular acidosis }\end{array}$ & $\begin{array}{l}407 \\
92\end{array}$ & 4 \\
\hline Genitourinary tract & $\begin{array}{l}\text { C-diarrhoea, constipation } \\
\text { O-peptic ulcer, chronic inflammatory bowel disorder, appendicitis, intestinal obstruction }\end{array}$ & $\begin{array}{l}1936 \\
124\end{array}$ & 18 \\
\hline Liver & $\begin{array}{l}\text { C-viral hepatitis, portal hypertension, drug induced hepatitis } \\
\text { O-hepatic abscess, hepatic failure, hydatid cyst liver, cholestatic jaundice in infancy }\end{array}$ & $\begin{array}{l}306 \\
28\end{array}$ & 3 \\
\hline Cardiovascular system & $\begin{array}{l}\text { C-acyanotic CHD (VSD, ASD, PDA, AS, PS), cyanotic CHD (TOF, Eisenmenger syndrome, } \\
\text { tricuspid atresia), RHD and Rheumatic carditis, CHF, myocarditis, pericarditis } \\
\text { O-infective endocarditis, hypertension, arrythmias, congenital heart defects (dextrocardia, } \\
\text { ectopia cordis) }\end{array}$ & 1532 & 14 \\
\hline Respiratory system & $\begin{array}{l}\text { C-acute respiratory infection, bronchial asthma, pleural effusion, lung abscess } \\
\text { O-hydatid cyst lung, pneumothorax, cystic fibrosis }\end{array}$ & $\begin{array}{l}2320 \\
56\end{array}$ & 20 \\
\hline Endocrine system & $\begin{array}{l}\text { C-hypothyroidism } \\
\text { O-diabetes mellitus (type 1), diabetes insipidus, precocious puberty }\end{array}$ & $\begin{array}{l}212 \\
28\end{array}$ & 2 \\
\hline Haematological system & $\begin{array}{l}\text { C-anaaemias (nutritional, thalassemias, aplastic), idiopathic thrombocytopenic purpura } \\
\text { O-haemophilia, leukaemia, lymphoma (Hodgkin's and non-Hodgkin's) }\end{array}$ & $\begin{array}{l}586 \\
48\end{array}$ & 5 \\
\hline Infectious diseases & $\begin{array}{l}\text { C-CNS infection, septicaemia, enteric fever, tuberculosis, acute rheumatic fever, chicken pox, } \\
\text { cutaneous leishmaniasis, malaria } \\
\text { O-brucellosis, mumps, measles, diphtheria, rabies, tetanus, Kalazar }\end{array}$ & 1526 & 15 \\
\hline Nutritional disorders & $\begin{array}{l}\text { C-protein malnutrition, rickets } \\
\text { O-scurvy, iodine deficiency goitre }\end{array}$ & $\begin{array}{l}2786 \\
42\end{array}$ & 24 \\
\hline $\begin{array}{l}\text { Genetic and metabolic } \\
\text { disorder }\end{array}$ & $\begin{array}{l}\text { C-Down's syndrome } \\
\text { O - storage disorders(glycogen/lipid) }\end{array}$ & $\begin{array}{l}224 \\
39\end{array}$ & 2 \\
\hline $\begin{array}{l}\text { Collagen vascular and } \\
\text { skeletal disorders }\end{array}$ & $\begin{array}{l}\text { C-rheumatoid arthritis, septic arthritis } \\
\text { O-congenital bony defects (CTEV, congenital dislocation of hip), Henoch schonlein purpura }\end{array}$ & $\begin{array}{l}96 \\
18\end{array}$ & 1 \\
\hline Psychological disorders & $\begin{array}{l}\text { C-post-traumatic stress disorders, behavioural disorders } \\
\text { O-ADHD, sepression }\end{array}$ & $\begin{array}{l}383 \\
65\end{array}$ & 4 \\
\hline $\begin{array}{l}\text { Eye, ENT, and skin } \\
\text { disorders }\end{array}$ & $\begin{array}{l}\text { C-scabies, atopic and seborrheic dermatitis, ASOM, congenital nasolacrimal duct obstruction, } \\
\text { superficial fungal infection, tonsillitis } \\
\text { O-Steven's Johnson syndrome }\end{array}$ & $\begin{array}{l}346 \\
6\end{array}$ & 3 \\
\hline Miscellaneous & Poisonings, scorpion bite, etc & 84 & $<1$ \\
\hline
\end{tabular}

stress disorder as a consequence of experiencing parental loss in war. ${ }^{8}$ A landmark survey by Unicef on the affect of war on children aged 8-18 years in Kabul showed that $41 \%$ had lost one or more parents because of the conflict, and over half had witnessed torture or violent death. ${ }^{9}$ While such events can lead to considerable psychological trauma or distress, they may also inure a young mind to violence.

Primary and secondary health care systems for children in Afghanistan are barely functional. Integration of community and hospital health care for children is promoted as the key strategy, with a particular emphasis on continuing medical education and morale building in local staff to maintain the practice of paediatrics in the country..$^{10}$ Most of the trained paediatricians are based in the hospitals and they do not realise the importance of preventing illness and accidents in the community. In rural areas, the supply of trained health personnel is non-existent. For every 10000 people in the country, there is an average of 1.8 physicians. Because three quarters of the physician population is in or near Kabul, most provinces have less than one physician for every 10000 people. Hence an integrated health service that promotes the health of all children in society has to be developed.

\begin{tabular}{|c|c|c|c|c|}
\hline & Number & Number & & \\
\hline Disease & $\begin{array}{l}\text { In term } \\
\text { babies }\end{array}$ & $\begin{array}{l}\text { In preterm } \\
\text { baby }\end{array}$ & Total & $\%$ \\
\hline Birth asphyxia & 1167 & 453 & 1620 & 28 \\
\hline Septicaemia/CNS infection & 823 & 685 & 1508 & 26 \\
\hline Pathological jaundice & 386 & 190 & 576 & 10 \\
\hline $\begin{array}{l}\text { Respiratory distress (congenital pneumonia, TTNB, HMD, } \\
\text { meconium aspiration, CHD) }\end{array}$ & 794 & 252 & 1046 & 18 \\
\hline Seizures & 202 & 140 & 342 & 6 \\
\hline Hypothermia & 96 & 129 & 225 & 4 \\
\hline Hypoglycaemia & 142 & 145 & 287 & 5 \\
\hline Haematological disorders (HDN, DIC, polycythemia) & 98 & 66 & 164 & 3 \\
\hline Multiple pregnancy & 44 & 21 & 65 & 1 \\
\hline $\begin{array}{l}\text { Birth defects (anorectal malformation, neural tube defect, } \\
\text { tracheo-oesophageal fistula, cleft lip/palate, pyloric stenosis, }\end{array}$ & 224 & 234 & 458 & 8 \\
\hline $\begin{array}{l}\text { Intestinal obstruction, billary afresia, omphalocoele, efc) } \\
\text { Miscellaneous }\end{array}$ & 76 & 28 & 104 & 2 \\
\hline
\end{tabular}


Table 4 Mortality in children (1 month-12 years): (number of deaths: 1620)

\begin{tabular}{llll}
\hline Disease & Number & $\%$ & Case fatality (\%) \\
\hline Septicaemia & 407 & 25 & 45 \\
CNS Infection & 240 & 15 & 40 \\
Diarrhoea & 292 & 18 & 22 \\
Acute respiratory infection & 356 & 22 & 16 \\
CHD, CHF, infective endocarditis & 243 & 15 & 14 \\
Renal failure & 32 & 2 & 30 \\
Hepatic failure & 7 & $<1$ & 50 \\
Diabetic ketoacidosis & 10 & $<1$ & 44 \\
Malignancies & 33 & 2 & 60 \\
\hline
\end{tabular}

Table 5 Neonatal mortality (number of deaths 1026)

\begin{tabular}{|c|c|c|c|c|c|c|}
\hline \multirow[b]{2}{*}{ Disease } & \multicolumn{2}{|c|}{ In term babies } & \multicolumn{2}{|c|}{ In preterm babies } & \multirow[b]{2}{*}{ Total number } & \multirow[b]{2}{*}{$\%$} \\
\hline & Number & Case fatality (\%) & Number & Case fatality (\%) & & \\
\hline Septicaemia & 176 & 30 & 152 & 36 & 328 & 32 \\
\hline Meningitis & 18 & 22 & 43 & 33 & 61 & 6 \\
\hline Birth asphyxia & 56 & 5 & 199 & 44 & 205 & 20 \\
\hline Respiratory distress & 125 & 16 & 179 & 56 & 267 & 26 \\
\hline Hypoglycaemia & 9 & 6 & 31 & 21 & 40 & 4 \\
\hline Hypothermia & 18 & 18 & 24 & 19 & 42 & 4 \\
\hline Congenital defects & 12 & 6 & 41 & 18 & 63 & 6 \\
\hline Haematological disorders & 8 & 8 & 12 & 18 & 20 & 2 \\
\hline
\end{tabular}

\section{Key points}

- There is complete breakdown of the health system in Afghanistan because of the affect of continuing war in the past 20 years.

- Much needs to be done to improve the health care services for children in Afghanistan and reduce the disease morbidity and mortality attributable to preventable/curable diseases.

The lack of basic needs such as food, shelter, clean water, health care access, education, and work opportunities is the biggest health challenge. Small steps are unlikely to provide any meaningful dividend and concerted or dedicated efforts of paediatricians cannot be harnessed to provide integrated child care services unless the chaotic situation is corrected by creating some semblance of law and order in Afghanistan-a bleeding and (slowly but surely) dying country.

\section{ACKNOWLEDGEMENTS}

I wish to acknowledge the Ministry of Public Health (MOPH), Afghanistan for their cooperation and help with the study. Sincere thanks to Dr Syed Ali Shah and Dr Ruhllah Rasikh, Directors, IGICH, Kabul for the logistics support and their help in data compilation. The paediatricians and residents in the department of Pediatrics, IGICH, Kabul deserve special mention. Finally, I thank the nursing and paramedical staff of IGICH for their active participation without which this study could not have been possible.

\section{Authors' affiliations}

A N Prasad, Department of Paediatrics, and institution, Indira Gandhi Institute of Child Health, Kabul, Afghanistan

Funding: none.

Competing interests: none declared.

Details of contribution: ANP analysed the data and wrote the manuscript. ANP will act as guarantor of the study.

Correspondence to: Lt Col A N Prasad, Department of Paediatrics, Military Hospital, Mhow (Indore) - 453441, India; amarendraprasad@rediffmail.com

Accepted for publication 25 July 2005

\section{REFERENCES}

1 Sogan D, Bridel J, Shepherd C, et al. 21 st century health care for children in Afghanistan. Pediatrics 1998;102:1193-8.

2 Unicef. Annual report on infant mortality rates. New York: Unicef, 2002.

3 Gessner BD. Mortality rates, causes of death, and health status among displaced and resident populations of Kabul, Afghanistan. JAMA 1994;272:382-5.

4 Singh $M$. Health status of children in Afghanistan. Indian Pediatr 1983;20:317-23.

5 Plunkett MCB, Southall DP. War and children. Arch Dis Child 1998;78:72-7.

6 World Health Organisation. An infrastructure and health atlas of Afghanistan. Geneva: WHO, 2002.

7 Ministry of Health. Afghan national health resources assessment. Kabul, Afghanistan: Ministry of Health, 2002.

8 Zulfiqar Ahmed Bhutta. Children of war: the real casualties of the Afghan conflict. BMJ 2002;324:349-52.

9 Gupta L. Psychosocial assessment of children exposed to war related violence in Kabul. New York: Unicef, 1997.

10 Brigg R, Thorsten F, Prochnow T, et al. Provision of health care in rural Afghanistan: needs and challenges. Am J Public Health 2004;94:1686-8. 